\title{
Adolescent Males' Aggressive Sexual Behaviour and Traditional Norms
}

\author{
M. Notole \\ J.G. Kheswa \\ Department of Psychology, University of Fort Hare, Private BagX1314, Alice, South Africa \\ Email: jkheswa@ufh.ac.za; Email: 201004723@ufh.ac.za
}

\section{Doi:10.5901/mjss.2014.v5n20p2799}

\begin{abstract}
Adolescent males who harbour aggression, show conformity to peers, less social skills and resentment towards their parents, tend to have propensity to display anti-social behaviour. Based on gender-strain theory, they indulge in alcohol and express their hegemonic masculinity by being involved with multiple sexual partners. To investigate the causal factors and outcomes of sexual aggressive behaviour, nine adolescent males (doing Grade 11), were purposively selected from one secondary school in Eastern Cape, South Africa. This paper employed an explorative qualitative approach and adhered to the following ethics; informed consent, confidentiality and protection from harm to safeguard the dignity of the participants. The findings revealed that inadequate parental guidance from permissive and authoritarian parents, peer influence and alcohol abuse are factors disinhibiting sexual aggressive behaviour among youth. Recommendations are that sex-education should be taught at schools and parents should communicate with their children.
\end{abstract}

Keywords: Sexual aggression, adolescent males, culture, peers.

\section{Introduction}

In South Africa, adolescents and young people constitute $26 \%$ of the country's population. In research by Burton (2007) adolescence (age between13-18) is the peak stage for both offending and victimization of sexual offences. Adolescence refers to that stage of human development that follows middle childhood and serves as the transition from childhood to adulthood and marked by rapid changes in emotional, physiological and cognitive development (Swartz, de la Rey, Duncan \& Townsend, 2008). Adolescents start with the onset, of the biological changes of puberty and ends with cultural identity of adulthood. Puberty is defined as a period of rapid physical maturation involving hormonal and bodily changes that happens during early adolescents (Papalia, Olds \& Feldman, 2009). There are internal and external changes that happen in adolescence body known as primary sexual characteristics and secondary sexual characteristics. Adolescent growth spurt controls the circulation of hormones during adolescence (Sigelman \& Rider, 2009), and penis and scrotum become larger, pubic hair develops and boys begin to experience wet dreams(nocturnal emission) as a sign that they can produce offspring should they engage in unsafe sex with females ( Louw \& Louw, 2007; Weitin, 2013). Drawing from gender role strain theory by Agnew (2006), which is based on the concept that male sexual behaviours are influenced by cultural norms females may even be afraid to negotiate safe sex. Males believe that risk taking is an expression of masculinity and permits them to have casual sexual relationships, practice unsafe sex and indulge in alcohol use (Jewkes, 2012). Owing to cultural influences, poor parental supervision, peer pressure and substance abuse, an alarming proportion of adolescent males tend act impulsively and violate the rights of others (Jewkes, 2012; Lussier \& Healey, 2010). Slotboom, Hendrik and Verbruggen (2011) are of the opinion that sexual aggression of adolescent males emanates from unresolved childhood experiences of sexual exploitation, neglect and physical abuse, which lead to feelings of worthlessness. As postulated by Sigmund Freud's psychoanalytic theory, lack of support and toilet -training during the second stage of psycho-sexual development, may give rise to an anal- aggressive personality formation. In other words, while children advance with age, they may be sadistic, hostile, disorderly and impulsive (Swartz et al., 2008). To derive sexual pleasure and compensate for emotional inadequacy, such youth tend to sexually coerce their counterparts without considering the possible consequences (e.g HIVIAids, unplanned fatherhood, imprisonment) (Schultz \& Schultz, 2013). No wonder in South Africa, one of the causal factors of aggressive sexual behaviour which results to rape, is influenced by gender based violence and precipitates the spread of HIV (Phaswana, Seage, Peltzer, Jooste \& Mkhonto, 2010).

Abroad and in the African continent, aggressive sexual behaviour is a rising concern especially for rural adolescent 
males. In Canada, a quantitative study of 100 adolescent students by Lussier and Healey (2010) revealed that sexual violence represents the persistent and escalating antisocial route. In Swaziland, majority of females are not capable to enforce the use of neither condoms in consensual sex nor abstinence in their sexual relationships until marriage. Based on the cultural precepts, females are expected to remain subservient and not to exercise their autonomy. This notion is perpetrated by patriarchy as part of culture and this, in turn, conditions adolescent males to model their male adults in the society and aggressively coerce their female counterparts (Ziyane \& Ehlers, 2006). Jeriphanos, Kudakwashe and Phinias (2004), confirm that, in African cultures, majority of males tend to misinterpret woman or a girl if she says "no" to sex, and end up raping them. Furthermore, Petersen, Bhana and McKay (2005), found that, in relation to cultural or environmental influences, boys were reportedly socialized from an early age into traditional patriarchal notions of masculinity, which promote and legitimize unequal gendered power relations. Also, in Zimbabwe, Gwirayi (2013) found that the high rate of child sexual abuse is not only linked to adults, but adolescent males as well. They were reported having interpersonal problems, low self- esteem and raised in poverty-stricken environment characterised by alcohol and drugs. Thus, they displaced their frustration, anger and emotional inadequacy on the female sexual partners.

In the Eastern Cape, aggressive sexual behaviour of adolescent boys has gradually become under spotlight due to the negative consequences it has on the youth (Swart et al., 2008). Eastern Cape is predominantly rural, consequently has increased the probability of male adolescents to engage in aggressive sexual activities. In support of this, Mwinga (2012) revealed that sexual aggressive behaviour is a common practice amongst rural secondary school adolescent males.

\section{Conceptual Framework}

The current study is underpinned by the Bronfenbrenner's ecological systemic theory, an integrated approach which involves the collective interaction of an individual with his/her family and acquaintances (Visser \& Moleko, 2012). According to ecological approach, family's economic level, parental supervision and peer relationship may contribute to sexual aggression of adolescent males, since during adolescence, youth undergo emotional, physical and cognitive changes and is expected to adapt to the cultural expectations (Nicholas, 2008; Swart et al., 2010). Through socialization, Kann (2008) posits that adolescent males may be easily influenced by how adults in the community interact. And if adults' behaviour is dominated by violence, low-moral values and alcohol abuse, youth may, in turn, adopt such behaviour as acceptable and attempt to experiment with alcohol by attending taverns (Louw \& Louw, 2007). Drawing from social learning theory developed by Bandura (1977), human behaviour is a result of interaction with the environment, personal factors and the behaviour itself (Weiten, 2013). Among the environmental factors that may influence the behaviour of adolescent males, Bandura identified modelling as having profound effect (Pastorino \& Doyle- Portillo, 2011). Adolescent males tend to imitate what adults/parents and/or peers do, and not what they say (Iriyama, Nakahara, Jimba, Ichikawa \& Wakai, 2007). Through modelling, these adolescents not only learn attitudes and emotions, but inappropriate behaviour as well (Louw \& Louw, 2007; Swartz et al., 2011). According to Burgard and Lee-Rife (2008), unhealthy practices such as substance use and women abuse are common in communities characterized by economic deprivation, where there could be a lack of good role models to demonstrate the advantages of staying in schools, refraining from risk- taking activities, and avoiding early parenthood. For example, in a study conducted in Cape Town amongst Grade 8- 11 learners, Holburn and Eddy (2011) found that $21 \%$ of adolescent males who grew up seeing verbal and physical fights between parents, were reported to be perpetrators of violence against their partners and another $16 \%$ of youth further reported to physically fight their partners in the future should they (i.e. sexual partners) anger them.

Various scholars found that adolescent males who are involved in gangs were twice as likely to abuse their sexual partners as compared to adolescents who do not belong to gangs, demonstrate deindividuation, carry knives and attend school irregularly (Breet, Myburgh \& Poggenpoel, 2010; Langa, 2010; Louw \& Louw, 2007; Mwinga, 2012). In support of the above, Holborn and Eddy (2011) posited that behavioural problems of adolescents are intertwined. Substance abuse and sexual misbehaviour are worsened by dysfunctional families and drug-friendly neighbourhoods. Previous studies, employed quantitative research method to investigate rape perpetration by adolescent males but did not address what must be done to ensure safe sex and good behaviour of adolescent boys (Kaufman, Kaufman, Dringus, Weiss, DelanyMoretlw \& Ross, 2013; Phaswana et al., 2010). In the current study, the researchers followed the qualitative research paradigm as it is preferable to get in-depth understanding of aggressive sexual behaviour of adolescent boys in rural high schools, and to suggest intervention strategies in dealing with such behaviour.

It is against this background that this paper seeks to answer the following questions:

- "What influences adolescent males to be sexually aggressive?"

- What are the dangers of sexual aggressive behaviour?" 


\section{Research Method}

In this study the researchers utilised qualitative approach, designed to explore and describe facts. The qualitative design allows participants to explain their own experiences and to present them using their own words, in a natural setting (Leedy \& Ormrod, 2005). This has been achieved by using open ended questionnaires which enabled the researchers to gather data with rich descriptions. Therefore, the prime purpose was to understand the multiplicity of explanations and the underlying processes that influence sexual aggression of adolescent males.

\subsection{Research population and sample}

Population is defined as the compilation of research components from which sample is to be drawn (Sanders, 2010). Therefore, in order for the sample to be representative, the researcher must make sure that sample is cautiously selected with exact qualities of the population as suggested by Creswell (2005). Knowing specified aim of the study, the population comprised of nine Black African Xhosa-speaking male adolescents whose age ranged from 15 to19 years of age, studying in one rural high school in Eastern Cape Province, South Africa. Participants were in grade 11. The grade 12 learners were excluded because they were busy with extra-lessons, in preparation for the final examination. As suggested by Elmes, Kantowitz and Roediger (2012), the participants were purposively selected to enable the researcher to carefully choose adolescent males who would provide the most pertinent information about the topic under investigation. Since the research project formed part of Psychology Honours degree, the principle of parsimony (choosing the simplest explanation of the phenomenon) was considered (Nicholas, 2008)

\subsection{Instrument}

From a qualitative standpoint, open-ended questionnaires were preferred considering their distinct advantages for the study of human behaviour. According to Creswell (2005) participants are able to complete the questionnaires in writing, which facilitates disclosure on their ideas, experiences and feelings, and thus allows sexual aggression of male adolescents to be explored. Despite the advantages, the deficiency of open-ended questionnaires was that some participants required further questioning for them to elaborate (Sanders, 2010).

\subsection{Materials}

A structured questionnaire was developed and validated by the study-leader, who is an expert in sexual behaviour of adolescent males to ensure objectivity. The questionnaire consisted of a sequence of the core questions to sexual aggression.

\section{Trustworthiness}

In establishing reliability of qualitative research study, four different constructs pioneered by Guba and Lincoln (Leedy \& Ormrod, 2005) were followed to guarantee validity of the study. These alternative criteria of trustworthiness are: credibility, generalisability, dependability and confirmability, which will be briefly discussed as follows:

- Credibility: Credibility is refers to the accuracy of data that reflects reality (de Vos, Fouche, Strydom \& Delport, 2011). In the current research study, the participants were monitored when completing the openended questionnaires to ensure credible findings as suggested by Creswell (2009).

- Generalisability: Generalisability is an extent to which generalizations can be made from obtained findings of sampled participants to the population (de Vos et al., 2011). The participants shared the same characteristics (e.g. similar cultural values, gender, race and language) which permit findings to be made into broader conclusions.

- Dependability: Dependability reflects the truthfulness of the researchers in the collection and presentation of data (de Vos et al., 2011). For the purpose of this study, participants were asked questions which were in context of adolescents' behaviour that emanated from theories of development.

- Confirmability: Confirmability refers to the degree to which other researchers can possible confirm the research results (Leedy \& Ormrod, 2005). The researcher relied on detailed notes provided by participants as their responses had to be coded by means of axial coding from grounded theory approach. 


\section{Ethical Consideration}

The researchers acted in accordance with the ethical principles as they serve to preserve the safety, wellbeing, rights and dignity of the contributors who participated in the study, as suggested by Leedy and Ormrod (2005). The ethical guidelines are formulated to protect and maintain good relationship between the researcher and participants (Bernstein \& Penner, 2012; Mouton, 2012). The Psychology department in the faculty of Social Science and Humanities, University of Fort Hare (Alice Campus) authorized the study. Thereafter, the school principal was approached to grant the permission prior the research study. The consent forms for the participation were also extended to legal guardians of the nine adolescent males who voluntarily participated. According to McBurney and White (2010) participants must be informed earlier of what will happen and the processes that will be involved and furthermore, be told that they can cease participation at any time without being penalized since the study is voluntary. The questionnaires were filled by respondents from one high School in Ntselamanzi village, Eastern Cape, in October 2013. It was explained to the participants that their dignity is well respected and there will be no names attached to questionnaires to ensure anonymity. The logical efforts were made to reduce any discomfort and loss of self-esteem during the process of the study as suggested by Shaughnessy, Zechmeister and Zechmeister (2012). In view of the fact that the study sought to investigate a sensitive topic of male sexual aggression, research respondents were not exposed to any unjustifiable physical or psychological harm. Furthermore, respondents were told that data will only be used for research purposes, and when published in journals, no one will ever know about their identity, including their educators, peers and parents.

\section{Analysis}

The completion of questionnaires was scheduled to take sixty minutes, but time was extended by fifteen minutes to make seventy five minutes with the reason that, some respondents would take time to recall their past experience of sexual behavioural incidences. The questionnaires were transcribed in written form. As suggested by Hennink, Hutter and Bailey (2011), each transcript (questionnaire) necessitates several readings before beginning the analysis to identifying appropriate themes. For that reason, themes have been identified through coding. Coding is referred to as breaking data into appropriate analytical figures (Blanche et al., 2006). In line to that, Hennink et al. (2011) further argue that coding refers to substantiations that are derived from data. Consequently, these evidences were basically discussed by participants and identified by researchers through readings and interpretation of data. For the purpose of this study, the researchers cautiously studied data and separated it into logical and significant components (themes). The inductive approach was followed, since the study was not to test the hypothesis (as in the case of quantitative research).

\section{Discussion of Research Findings}

The correspondence and commonalities from the data required the formulation of themes with the aim to discuss the key factors leading to sexual aggression. Thus, identified themes were as follows;

\subsection{Permissive and authoritarian parenting styles}

The findings from participants revealed crucial attributes leading to sexual aggression of male adolescents. Most adolescent males tend to be sexually aggressive because of the way they have been raised by their parents. In view of the fact that parents are subsets of the family which is said to be an agency of socialization, parents have to play a role in addressing and educating adolescents about sexual related issues. Therefore, parenting styles are the central feature which cultivate or deter aggression. For example, permissive parenting style is found to be responsible for sexual aggressiveness of adolescent males residing in rural areas. Adolescents were asked: How do the family and societal environment contribute towards the high rate of sexual aggression of adolescent males? Participants responded differently with their clashing responses, with the understanding that not all participants were raised by permissive parents. Consequently, this brings to an understanding that accountable parents and communities take their responsibilities in educating their male adolescents and sensitise them against antisocial behaviours. However, it has been found that desensitised adolescents to aggression are most likely to be sexually aggressive to their partners. Additionally, the majority of adolescent males who concur that they have 'sexually coerced' their partners revealed that their parents do not care, while those who have been sexually educated by their parents and their societies revealed less propensity to sexual aggression. The responses obtained from participants were as follows: 
"My family and adults in my environment take responsibility to lecture me about the dangers of unsafe sex and say to me I must not have sex before time. I must wait for my good time."

In contrast to that, other participants responded as follows:

\begin{abstract}
"Some of the parents and educators don't care about their children and they don't even want to talk with them about sex. Even when watching television programmes- like Intersexion or Generations- that have sex, parents insist on watching news on SABC3 or comedy on E-tv"

"Because of culture, in Eastern Cape, our parents do not want to accept that we are sexually active and have relationships. They focus on guiding our sisters to take of themselves and ignore us. That is why we smoke and have many girlfriends just like our friends do"
\end{abstract}

For as long as adolescent males are not engaged in topics which address sexuality and psychological well-being, their attitudes and values towards sex will be permissive because they lack insight and self-assertion (James, Reddy, Taylor \& Jinabhai, 2004; Kigozi, 2006; Maluka, 2004; Mturi, 2001). The above reports by participants give evidence that Eastern Cape youth's sexual aggression especially among black adolescent males is rooted within culture. According to Burton (2007), poor communication about sexual related matters between parents and their male adolescents results in male youth being hostile towards their partners when deprived sex. Comparatively, if parents display warmth and consistent supervision to their children, they are expected to implant good behaviour and self control to their adolescent males. It is therefore clear that children of permissive parents are most likely to engage in risky sexual behaviours which put them at risk of contracting sexual infections including HIVIAIDS (Jansen, Moletsane, Neves, Soudien, Stroud, Swart \& Wild, 2012; Karla, 2010). Similarly, children of authoritarian parents are most likely to be sexual aggressive as compared to children who have been raised by parents who set clear rules, give guidance and provide consistent supervision (Kalat, 2010).

Arguably, permissive parents do not care and often neglect their children. Consequently, the failure of parental supervision leads to peer-influence, gangsterism and antisocial behaviours (Nicholas, 2008). This finding is aligned with the research by Kheswa (2006) who found that adolescent males from Soweto township indicated that their antisocial behaviour was a result of not experiencing positive communication with the caregivers because they were raised in families where values and principles were not emphasized by parents, hence they also drank alcohol.

\title{
7.2 Peer influence
}

Owing from poor parental supervision, adolescents who have been raised by negligent parents are at risk of being negatively influenced by their peers. Adolescents tend to be loose and get easily influenced by their peer friends. With regard to the question: "How does peer influence contribute towards the sexual behaviour among adolescent males?", the responses from this group of African adolescent males affirmed that their sexual aggression emanates from peer influence. For example, participants were quoted as saying:

\author{
"If my friends have girl friends, I must also have my girl friend too" \\ "It is because they force their friend to do sexual activities if you did not do it you will be laughed and called by names" \\ "Sometimes they are being pressured by their friends" \\ "I had to force her because my friends will say am weak and call me by names"
}

In view of these responses, Giddens (2009) is of the opinion that adolescent males reared in rigid and conservative households, tend to conform easily and resort to antisocial peer norms. To show their sexual prowess and hegemonic masculinity (Adams \& Govender, 2008; Bruce, 2005), they must sexually coerce their partners. Hegemony is a concept derived by Antonio Gramsci, that through socialization and cultural processes, males will demand power and oppose feminity to claim supremacy over women. Bank (2011) documented that sexual intimidation is most frequent when the peers are under the influence of alcohol and other illicit drugs. Furthermore, to claim their sense of belonging to the group members, they are expected to spend most of their time with peers (Mwinga, 2012). According to Jewkes (2012) adolescent males may feel compelled to jeopardize their own health, future-goals and sexual values by engaging in casual sexual relationships with multiple partners and violate their partners' rights without the knowledge of legal implications of statutory rape. To address this plight faced by youth who lack internal locus of control (a belief that reinforcement is brought about by one's own behaviour or an ability to make informed decisions and live by them) (Schultz \& Schultz, 2013), comprehensive parenting skills programmes and peer- resistance skills must be initiated by Lovelife and other Youth Organisations to jointly improve communication-skills within families, to enable adolescents to 
be self-assertive.

\subsection{Alcohol and Substance abuse}

Substance and alcohol abuse by adolescent males is an ordinary factor leading to sexual aggression. For example, with the question "Explain the reason leading adolescent males to rape sexual partners?" three male adolescents in their response emphasized that drug and alcohol advances impulsive behaviour. Participants were quoted as saying:

\footnotetext{
"I force myself when I am under the influence of alcohol and drugs and I feel that whatever I want I must get because she is my girlfriend."

"When I am drunk, I become sexually aroused and expect my partner not to refuse"

"When we are from the shebeen, I don't expect my girlfriend to leave me because I have bought her alcohol"
}

In view of the above reports by the participants, it is clear that drugs and alcohol influence are the leading causes of anti-social behaviour among adolescents. In a quantitative study conducted in Nkonkobe Municipality, Alice, South Africa, Takatshana (2013) found that alcohol abuse contributed towards adolescent males to be sexually active, inconsiderate and behave aggressively towards their counterparts. Burton (2010) documented that most South African adolescent males in the Eastern Cape grow up in neighbourhoods where drugs and alcohol are easily accessible, were psychologically more distressed and displayed recurrent social and interpersonal problems. Consequently, such reckless behaviours encompass sexual coercion (Zastrow \& Kirst-Ashman, 2007). This implies that when adolescents are under the influence of drugs and alcohol, they are most likely to engage in risky sexual practices. Drawing from alcohol myopic model, majority of adolescent males when intoxicated, their thinking becomes irrational and overwhelmed by the thought that they are invincible (Comer, 2013; Pastorino \& Doyle- Portillo, 2011). Similarly, in many parts of the world, as a result of alcohol abuse, an alarming proportion of youth fail to practice safe sex and become susceptible to the risk of contracting sexual infections (Garcia- Moreno, Jansen, Ellsberg, Heise \& Watts, 2006; Jewkes, Nduna, Shai \& Dunkle, 2011). Essau and Hutchinson (2008) also found that alcohol abuse among adolescent males is inextricably linked to impairment in various life areas, such as an increase in family conflict when advised to refrain from illicit drugs, sexual victimization of sexual partners and greater likelihood of psychopathology in adulthood.

\subsection{STIs and HIVIAIDS}

Previous studies advocate that there is a strong link between sexual aggression and sexual infectious diseases (e.g. syphilis, gonorrhoea, Chlamydia) (Holborn \& Eddy, 2011; Jewkes et al., 2011; Sussman, 2008). These participants revealed that force during sexual intercourse is the causative of drastic increase in numbers of people infected by STIs including HIVIAIDS. For example with regard to the question of consequences and outcomes of sexual aggression, the participants were quoted as saying:

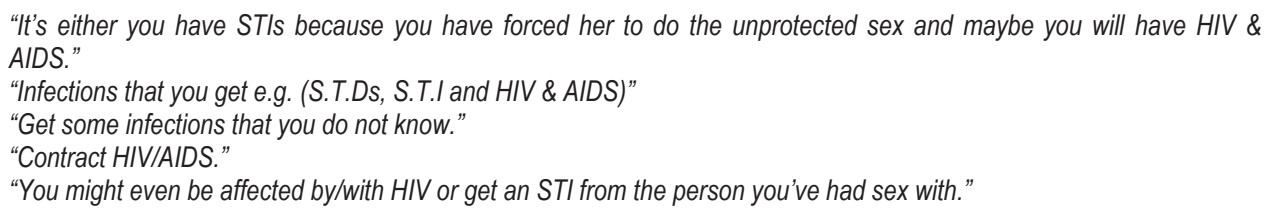

The bleak reports by respondents serve to substantiate that STIs including HIVIAIDS are the top global killer diseases mostly affecting the youth. In South Africa precisely in rural areas, figures of infected adolescents are progressively escalating and caused by sexual aggressiveness (Jewkes, 2012; Louw \& Louw, 2007). Other research by Kaufman et al., (2013) supports that sexual aggressive behaviour and HIVIAIDS have association. For example, in their survey of 1991 adolescent males in Grade 9 from 46 secondary schools in Cape Town and Port Elizabeth townships, $17.2 \%(\mathrm{~N}=342)$ of this vulnerable youth reported having perpetrated rape. Sadly, the victims are left with additional psychological effects which may include trauma, stress and unwanted pregnancy (Mwinga, 2012). The other implication could be that, they continue to re-infect themselves if they are unaware of their health- status, and do not use contraceptives. 


\subsection{Punishment, Imprisonment and Suicide}

For example with regard to the question that seeks to find the consequences and outcomes of aggressive sexual behaviour among adolescents males, participants were quoted as follows:

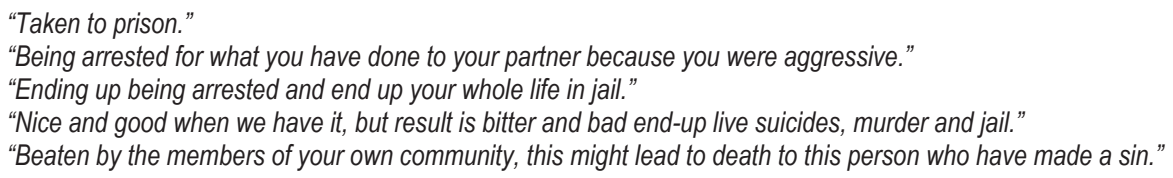

According to Stevens and Cloete (2010) antisocial behaviours can be restructured by means of inflicting punishment. In the context of sexual abuse, perpetrators are taken into prison. However, adolescents who are sexual offenders tend to be depressed by prison environment and the abuse, which left them with no other preference but to commit suicide (Nicholas, 2008; Steven, 2010).

\subsection{Possible limitations}

Despite the fact that this study addresses significant questions concerning sexual aggression of adolescent males in rural areas of the Eastern Cape, there are some limitations that ought to be considered. A possible limitation of this study is related to the time which was assigned for data collection. Participants were using transport to-and-from school, respondents had to withdraw from the study immediately when their transport arrives. Participants were all isiXhosa speaking male adolescents, thus language was a shortcoming since questionnaires had to be translated to isiXhosa for them to better understand the content of the question. For that reason, it can be argued that they do not represent a typical adolescent who sexual coerces their partners.

\section{Recommendations}

The findings of this study exhibits that when adolescents are not engaging in discussions about sexual related behaviours with their parents, male adolescents are likely to engage in risky sexual practices. Possible this risky sexual behaviours may adversely impact the psycho-social well being of the perpetrator and the victim, since the perpetrator might end-up imprisoned while victim left traumatized. It is therefore recommended that sexual education should be offered early by parents to children. The transmission of values to adolescents at school is of utmost importance in developing trust which enhances open communication, which enables educators to identify risk behaviour and seek intervention in-time. On the other hand, neighbours should make basic necessities (food, safety and entertainment) of their children available and be act responsibly. The Government and NGOs should formulate youth centres to promote awareness campaigns and encourage older men to support young adolescents to enhance good behaviour.

\section{Acknowledgements}

The authors gratefully acknowledge the adolescent males who participated in the study and financial support from the Govan Mbeki Research and Development Centre from UFH.

\section{References}

Adams, L.A., \& Govender, K. (2008). "Making a Perfect Man": traditional masculine ideology and perfectionism among adolescent boys. South African Journal of Psychology, Vol 38 (3), 551-562.

Agnew, R. (2006). Pressured into crime: an overview of general strain theory. Roxbury: Los Angeles

Bank, J. L. (2011). Home spaces, street styles: contesting power and identity in a South African city. South Africa: Wits University press (Pluto press).

Bernstein, C.S. \& Penner, R. (2012). Psychology. China: Wardsworth Cengage Learning.

Blanche, T. M., Durreim, K. \& Painter, D. (2006). Research in Practice: applied methods for social sciences. Cape Town: University of Cape Town Press.

Breet, L., Myburgh, C. \& Poggenpoel, M. (2010). The relationship between the perception of own locus of control and aggression of adolescent boys. South African journal of education: 30,511-526.

Bruce, H.H. (2005). Psuchology the essence of a science. New York: Pearson Education. 
Burton, P. (2007). Someone stole my smile: An exploration into the causes of youth violence in South Africa. Cape Town: Centre for justice and crime prevention.

Comer, R.J. (2009). Abnormal Psychology. (8th Edition). Worth Publishers: New York.

Creswell, J.W. (2005). Educational research. Planning, conducting and evaluating quantitative and qualitative research. (2nd edition.). Upper Saddle River, New Jersey: Pearson Prentice Hall.

de Vos, A.S., Fouche, C.B., Strydom, H. \& Delport, C.S.L. (2011). Research at grass roots. South Africa: Van Schaik.

Elmes, D., Kantowitz, B. H. \& Roediger, H. L. (2012). Research methods in Psychology. United Staes of America: Wadsworth Cengage Learning.

Essau, C.A., \& Hutchinson, D. (2008). Alcohol Use, Abuse and Dependence. [In C.A. Essau (Ed.). Adolescent Addiction. Epidemiology, Assessment, and Treatment, Inc. London, pp 61-116]

Garcia-Moreno, C., Jansen, H.A., Ellsberg, M., Heise, L.,\&Watts CH. (2006). Prevalence of intimate partner violence: findings from the WHO multi-country study on women's health and domestic violence. Lancet. 368(9543):1260---1269.

Giddens, A. (2009). Anthony Giddens sociology. United Kingdom: Polity Press.

Hennink, M. Hutter, I. \& Bailey, A. (2011). Qualitatvive research methods. London: Sage.

Holborn, L. \& Eddy, G. (2011). First Steps to healing the South African Family. A research paper by the South African Institute of Race Relations, Johannesburg.

Iriyama, S., Nakahara, S., Jimba, M., Ichikawa, M., \& Wakai, S. (2007). AIDS health beliefs and intention for sexual abstinence among male adolescents in Kathmandu, Nepal; A test of perceived severity and susceptibility. Journal Royal of Public Health, 121:64-72.

James, S., Reddy, S.P., Taylor, M \& Jinabhai, C.C. (2004). Young people, HIVIAIDS/STIS and sexuality in South Africa: the between awareness and behavior. Acta Paediaty, 93 (2):264-269.

Jansen, J., Moletsane, M., Neves, D., Soudien, C., Stroud, L., Swart, S. \& Wild, L. (2012). Child and adolescent development. South Africa: Oxford University Press.

Jeriphans, M., Kudakwashe, M., Phinias, T. (2004). Influences of culture on acquaintance rape among college students. Thesis, Zimbabwe University: Harare

Jewkes, R. (2012). Rape perpetration: a review in Pretoria, Sexual Violence Research Initiative. Pretoria: South Africa.

Jewkes, R., Nduna, M., Shai, N. J., \& Dunkle, K. (2012). Prospective study of rape perpetration by young South African men: incidence \& risk factors. PloS one, 7(5), e38210.

Kann, L. (2008). A dangerous game: male adolescent's perceptions and attitudes towards sexual consent. University of Witwatersrand: Johannesburg

Karla, K. (2010). Pretend Aggression in play, aggressive behaviour and parenting style. Western Cape.

Kaufman, Z. A., Kaufman, E. B., Dringus, S., Weiss, H. A., Delany-Moretlwe, S., \& Ross, D. A. (2013). P3. 387 Prevalence and Predictors of Rape Perpetration Among Male Secondary School. Students in Peri-Urban Xhosa Communities in South Africa. Sexually Transmitted Infections, 89 (Suppl 1), A270-A270.

Kheswa, J.G., (2006). A descriptive analysis of alcohol and drug use amongst in Soweto. (Unpublished MEd dissertation). Johannesburg: University of Johannesburg

Kigozi, N. G. (2006). The correlation between certain interpersonal relationships and the risky sexual behaviour of urban black adolescents. (Unpublished M. Sc. Dissertation). Bloemfontein: University of Free -State.

Langa, M. (2010). Adolescent's talk about absent fathers. Journal of Psychology in Africa , 20(4) 519- 526.

Leedy, P.D. \& Ormrod, J.E. (2005). Practical research planning and design. Pearson: Merrill Prentice Hall.

Louw, D. \& Louw, A. (2007). Child and adolescent development. The University of Free State: Bloemfontein.

Lussier, P. \& Healey, J (2010). Searching for the developmental origions of sexual violance. Canada: John Wiley \& Sons.

Maluka, C.S. (2004). Subjective well-being and self-esteem in a disadvantaged community. [Unpublished M.A. dissertation]. Pretoria: University of South Africa.

McBurney, D.H. \& White, T.L. (2010). Research methods. Wardsworth Cengage Learning: Unite State of America:

Mouton, J. (2012). Understanding social research. Van Schaik: Pretoria

Mturi, A.J. (2001). "Parents Attitudes to adolescent Sexual Behavior in Lesotho". Paper prepared for the XXIV General Population Conference, Salvador-Brazil, 18-24 August 2001

Mwinga, A. M. (2012). Factors contributing to unsafe sex among teenagers in the secondary schools of Botswana. South Africa: University of South Africa.

Nicholas, L. (2008). Introduction to Psychology. Cape Town: UCT Press

Papalia, D.E, Olds, S.W. \& Feldman, R.D. (2009). Human - Development. (11th edition).Boston: McGraw-Hill Companies, Inc.

Pastarino, E. \& Doyle- Portillo, S . (2011). What is Psychology. Wadsworth: Belmont

Phaswana, N., Seage, J., Peitzer, K., Jooste, S. \& Mkhonto, S. (2010). Social determinant of HIV in the Eastern Cape. Human research Council: Eastern Cape

Sanders, L. (2010). Discovering research methods in Psychology: A student's guide. Britain: BPS BlackWell.

Shaughnessy, J.J., Zechmeister, E.B. \& Zechmeister, J.S. (2012). Research methods in Psychology. Singapore: McGraw-Hill.

Slotboom, A.M., Hendrik, J. \& Verbruggen, J. (2011). Contrusting adolescent female and male sexual aggression . A self report study on prevalence and predictors of sexual aggression, Vol. 17 No.1 pp. 15-33.

Steven, L.B. (2010). Crime Prevention: Approaches, practices and evaluations. Anderson: United States of America.

Stevens, R. \& Cloete, M. G. T. (2010). Introduction to Criminology. South Africa: Oxford University Press. 
Sussman, S. (2008). Teen Sexual Addiction. [In C.A. Essau (Ed.). Adolescent Addiction.

Epidemiology, Assessment, and Treatment, Inc. London, pp 269-294]

Swartz, L., de la Rey, C., Duncan, N., \& Townsend, L. (2011). Psychology: an introduction. (3 ${ }^{\text {rd }}$ ed.). Oxford University Press Cape Town. Takatshana, S. (2013). The impact of alcohol on the sexual behaviour of adolescent males in Nkonkobe municipality. [M.Social Science Dissertation]. University of Fort Hare: Alice.

Visser \& Moleko (2012). Community psychology in South Africa. South Africa: Van Schaik.

Ward, T. (2002). Marshall and Barbaree's integrated theory of child sexual abuse: A critique. England: Routledge.

Weiten, W. (2013). Psychology. Themes and variations. South African Edition. Cengage Learning: Australia.

Zastrow, C., \& Kirst-Ashman K.K. (2007). Understanding human behaviour and the social environment. United States of America: Thomson Brooks/Cole.

Ziyane, I.S., \& Ehlers, V.J. (2006). Swazi youth attitudes and perceptions concerning adolescent pregnancies and contraception. Health S.A. Gesondheid, 11(1):31-42. 